\title{
Utilização de um complexo enzimático para rações contendo farelo de gérmen de milho desengordurado para suínos em fase de crescimento e terminação
}

\section{Enzymatic complex in feed containing defatted corn germ meal for pigs during the growth and finish phases}

\author{
Caio Abércio da Silva ${ }^{1 *}$; Sylvia LuizaVinokurovas²; Ana Maria Bridi"; \\ Alexandre Oba ${ }^{1}$; Graziela Drociunas Pacheco ${ }^{1}$; Arturo Pardo Lozano ${ }^{2}$; \\ Roberta Abrami Monteiro Silva²; Danyel Bueno Dalto²; Piero da Silva Agostini ${ }^{3}$
}

\section{Resumo}

O objetivo deste experimento foi avaliar a uso do farelo de gérmen de milho desengordurado (FGMD) em associação a um complexo enzimático (CE) nas rações de suínos em fase de crescimento e terminação sobre o desempenho, digestibilidade, características de carcaça, qualidade da carne e sobre parâmetros de eficiência econômica. Foram utilizados 50 suínos (Agroceres PIC), 25 machos castrados e 25 fêmeas, com peso médio inicial de $41,14 \pm 2,95 \mathrm{~kg}$. Os animais foram submetidos a cinco tratamentos experimentais: T1- ração controle (milho + farelo de soja); T2- ração com milho + farelo de soja $+20 \%$ FGMD (isonutriente e isoenergética em relação a T1) ; T3- ração com milho + farelo de soja + 20\% FGMD e CE (isonutriente e isoenergética em relação a T1); T4- ração com milho + farelo de soja + 20\% FGMD sem CE (formulada igual a T3, descontada a matriz nutricional do CE, com menores níveis nutricionais e energéticos que T1); T5- ração com milho + farelo de soja + 20\% FGMD e CE (formulada igual a T2, com o CE adicionado na forma on top, apresentando valores nutricionais e energéticos superiores a T1). O delineamento experimental foi em blocos casualizados, com 5 tratamentos e 5 repetições, sendo cada baia com dois animais de diferentes sexos a unidade experimental. Foi verificada diferença significativa $(\mathrm{p}<0,05)$ para o ganho médio de peso, com melhores resultados para T5 e piores para T4. Para a conversão alimentar o pior resultado observado foi para $\mathrm{T} 4(\mathrm{P}<0,05)$. Os maiores valores de $\mathrm{pH}$ final da carne foram observados para $\mathrm{T} 1$, mas influencias deste parâmetro sobre a qualidade da carne não foram verificadas para nenhum dos tratamentos. Na avaliação econômica os melhores resultados foram observados para T3. A adição do complexo enzimático em dietas de suínos em crescimento e terminação contendo a inclusão de $20 \%$ de FGMD melhorou o desempenho zootécnico sem comprometer as características de carcaça e de qualidade da carne, demonstrando vantagens econômicas.

Palavras-chave: Alimento alternativo, fitase, qualidade da carne, xilanase

\begin{abstract}
The aim of this experiment was to evaluate the use of defatted corn germ meal (DCGM) with an enzymatic complex (EC) in feed for pigs in growing and finishing phases on the performance, digestibility, carcass,
\end{abstract}

${ }^{1}$ Profs. Drs. do Dept ${ }^{\circ}$ de Zootecnia, Universidade Estadual de Londrina, UEL, Londrina, PR. E-mail: casilva@uel; ambridi@uel. br; oba@uel.br; grazivetuel@hotmail.com

${ }^{2}$ Discentes do Programa de Pós-Graduação em Ciência Animal, UEL, Londrina, PR. E-mail: luzinhav@hotmail.com; setaarturol@ hotmail.com; roberta_a_silva@cargill.com; danyelbd@hotmail.com

${ }^{3}$ Discente de Doutorado do Dept ${ }^{\circ}$ de Ciência Animal, Universidade Autônoma de Barcelona, Barcelona. E-mail: pieroagostini@ hotmail.com

* Autor para correspondência 
meat quality and economic efficiency characteristics. A total of 50 pigs (Agroceres PIC), 25 castrated male and 25 female, with initial average weight of $41.14 \pm 2.95 \mathrm{~kg}$, were used The animals were submitted to 5 treatments: T1- control feed (corn + soya meal), T2- ration with corn + soybean meal + $20 \%$ DCGM (isonutrient and isoenergetic compared to T1), T3- ration with corn + soybean meal $+20 \%$ DCGM and CE (isonutrient and isoenergetic compared to T1), T4 - ration with corn + soybean meal + $20 \%$ DCGM without EC (formulated equal T3, without considering the nutritional matrix of CE, with lower nutritional and energetic levels than T1), T5-ration with corn + soybean meal $+20 \%$ DCGM and EC (formulated equal T2, with EC added in on top form, presenting higher nutritional and energetic levels than T1). The experimental design was in random blocks, with 5 treatments and 5 repetitions per treatment, being each pen with two animals of different genders considered an experimental unit. Significant difference was verified for average weight gain when was considered the entire experimental period, with advantages for T5 and worst results for T4. For feed conversion, the worst result was verified in $\mathrm{T} 4(\mathrm{P}<0.05)$. The highest final $\mathrm{pH}$ values for meat were observed for $\mathrm{T} 1$, but influences from this parameter could not be verified (in any of the treatments) on the quality of the meat. Economic evaluations have shown best results for T3. Adding the enzymatic complex to diets in growing and finishing pigs with 20\% DCGM has improved the zoo-technical performance without compromising carcass characteristic neither meat quality, with an increase in economic feasibility.

Key words: Alternative feed, phytase, meat quality, xylanase

\section{Introdução}

$\mathrm{Na}$ suinocultura brasileira a maior parte dos custos de produção provém da alimentação, constituída basicamente pelo milho e pelo farelo de soja, commodities que sujeitas às instabilidades de preços podem comprometer a economia do setor. Estes ingredientes são considerados padrões quando comparados com os valores nutricionais de alimentos denominados alternativos, que oportunamente participam das formulações de ração destinadas aos suínos (BEM-HAMED; SEDDIGHI; THOMAS, 2011). Neste contexto, sua utilização resulta com freqüência em índices inferiores de desempenho, quando comparados com rações à base de milho e de farelo de soja, porém com um cenário econômico muitas vezes interessante para o produtor (FERREIRA; ARAÚJO; SILVA, 2007).

Neste sentido, a busca por ingredientes alternativos viáveis ou que possam ter o seu valor nutritivo melhorado através do uso de enzimas exógenas é um procedimento bastante comum atualmente. Estes complexos enzimáticos, via de regra, favorecem o aproveitamento energético e nutricional de compostos como os polissacarídeos não-amiláceos e oligossacarídeos, além de diminuir a excreção de nutrientes não digeridos (BEDFORD, 2000).
Neste cenário, o farelo de gérmen de milho desengordurado (FGMD), um co-produto resultante da indústria de extração de óleo do milho, com muitos atrativos nutricionais e significativa disponibilidade na região centro-sul do Brasil, pode ser utilizado em rações de suínos em fase de crescimento e terminação com êxito no desempenho (SOARES et al., 2004; COSTA et al., 2011; PACHECO et al., 2012), não obstante apresente restrições devido aos altos teores de fibra e a baixa energia, aspectos que demandam correções que podem encarecer a ração que utiliza este ingrediente (MOREIRA et al., 2002). Assim, a inclusão de um complexo enzimático em uma ração que tenha a participação do FGMD poderia contribuir para uma otimização do ingrediente, favorecendo os resultados e a viabilidade do seu uso.

Trabalhando com ingredientes substitutos do milho em rações de suínos em fase de crescimento e terminação, Genlai, Xiao e Mingxin (2009) observaram que a suplementação enzimática destas rações resultou em melhoras no desempenho animal e promoveu a redução no custo da alimentação, determinando um maior retorno econômico.

Embora existam estudos sobre a utilização do FGMD em substituição ao milho em dietas para 
suínos, não há avaliações que tratam dos efeitos da adição de enzimas exógenas em rações que contenham este ingrediente. Assim, este trabalho tem por objetivo avaliar os efeitos do uso de um complexo enzimático em rações de suínos em fase de crescimento e terminação que contenham a inclusão de $20 \%$ de FGMD sobre parâmetros de desempenho, digestibilidade, carcaça e de qualidade da carne.

\section{Material e Métodos}

Foram utilizados 50 suínos da genética Agroceres-PIC, sendo 25 machos castrados e 25 fêmeas, com média de 84 dias de idade e peso médio inicial de $41,14 \pm 2,95 \mathrm{~kg}$. Os animais foram alojados em baias de alvenaria com piso compacto com $3 \mathrm{~m}^{2}$, sendo dois animais de gêneros diferentes por baia, onde receberam água e ração à vontade durante todo o período experimental, cuja duração foi de 83 dias.

O delineamento experimental foi em blocos casualisados, sendo estabelecidos cinco blocos baseados no peso inicial dos animais, com cinco repetições por tratamento, onde cada baia representou uma unidade experimental.

As variáveis de desempenho analisadas foram o ganho diário de peso (GDP), consumo diário de ração (CDR) e conversão alimentar (CA).

Os tratamentos foram compostos por cinco rações formuladas visando atender as exigências mínimas para suínos fêmeas de alto potencial genético com desempenho superior, segundo Rostagno et al. (2005), subdividindo as necessidades nutricionais dos animais em três faixas de peso: entre 30 e $50 \mathrm{~kg}$ de peso vivo (Crescimento I), entre 50 e $70 \mathrm{~kg}$ de peso vivo (Crescimento II) e entre 70 e $100 \mathrm{~kg}$ de peso vivo (Terminação).

Uma ração denominada Controle (T1) foi formulada à base de milho e farelo de soja e as demais elaboradas com milho, farelo de soja e
$20 \%$ de farelo de gérmen de milho desengordurado (FGMD). Na ração T2, formulada com milho, farelo de soja e $20 \%$ de farelo de gérmen de milho desengordurado (FGMD), os valores nutricionais eram idênticos à ração T1. Duas rações que continham o FGMD receberam o complexo enzimático comercial Allzyme ${ }^{\circledR}$ SSF (pectinase - $4000 \mu / \mathrm{g}$, protease $-700 \mu / \mathrm{g}$, fitase $300 \mu / \mathrm{g}$, ß-glucanase - $200 \mu / \mathrm{g}$, xilanase - $100 \mu / \mathrm{g}$,

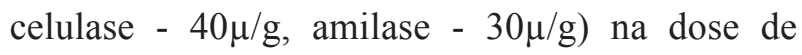
$0,02 \%$, sendo considerada em uma destas rações (T3) o valor nutricional fornecido pela matriz do complexo enzimático, segundo orientações da Alltech $^{\circledR}$, resultando em uma ração isonutriente e isoenergética, comparada com a ração Controle (T1). Na ração T4 foi utilizada a mesma fórmula da ração T3, porém sem a inclusão do complexo enzimático, resultando em uma ração com menores níveis nutricionais e energéticos que a ração Controle (T1). Na ração T5 foi utilizada a mesma formulação da ração T2 mais o complexo adicionado on top, excedendo, portanto, os níveis nutricionais e energéticos da ração Controle (T1). Assim, foram definidos os seguintes tratamentos:

T1: Ração Controle (milho + farelo de soja);

T2: Ração com 20\% FGMD;

T3: Ração com 20\% FGMD, com complexo enzimático (sendo considerado o valor nutricional da matriz do complexo enzimático);

T4: Ração com 20\% FGMD, sem complexo enzimático (reformulada com desconto do valor nutricional da matriz do complexo enzimático da ração);

T5: Ração com 20\% FGMD, com complexo enzimático on top (com incremento nutricional dado pelo valor da matriz do complexo enzimático).

A composição percentual e os valores calculados das rações experimentais para as fases de Crescimento I, Crescimento II e Terminação encontram-se respectivamente nas Tabelas 1,2 e 3 . 
Tabela 1. Composição percentual e calculada da ração experimental de suínos na fase Crescimento I.

\begin{tabular}{|c|c|c|c|c|c|}
\hline \multirow{2}{*}{ Ingredientes (\%) } & \multicolumn{5}{|c|}{ Tratamentos } \\
\hline & Controle & FGMD $^{1}$ & $\begin{array}{r}\text { FGMD } \\
\mathrm{c} / \mathrm{CE}^{4} \\
\end{array}$ & $\begin{array}{l}\text { FGMD s/ CE } \\
\text { reformulado }\end{array}$ & $\begin{array}{c}\text { FGMD c/ CE } \\
(\text { on top })\end{array}$ \\
\hline Milho grão & 68,32 & 46,92 & 49,65 & 49,65 & 46,92 \\
\hline Farelo de soja $45 \%$ & 28,24 & 27,28 & 26,34 & 26,34 & 27,28 \\
\hline FGMD $^{1}$ & 0,00 & 20,00 & 20,00 & 20,00 & 20,00 \\
\hline Óleo de soja & 0,32 & 2,56 & 1,22 & 1,22 & 2,56 \\
\hline Fosfato Bicálcico & 1,22 & 1,13 & 0,59 & 0,59 & 1,13 \\
\hline Calcário & 0,56 & 0,61 & 0,71 & 0,71 & 0,61 \\
\hline L-Lisina & 0,39 & 0,42 & 0,42 & 0,42 & 0,42 \\
\hline Premix Vitamínico² & 0,30 & 0,30 & 0,30 & 0,30 & 0,30 \\
\hline Sal comum & 0,25 & 0,25 & 0,25 & 0,25 & 0,25 \\
\hline DL-Metionina & 0,14 & 0,20 & 0,19 & 0,19 & 0,20 \\
\hline L-Treonina & 0,14 & 0,19 & 0,19 & 0,19 & 0,19 \\
\hline Premix Mineral $^{3}$ & 0,10 & 0,10 & 0,10 & 0,10 & 0,10 \\
\hline L-Triptofano & 0,00 & 0,02 & 0,02 & 0,02 & 0,02 \\
\hline Inerte & 0,02 & 0,02 & 0,00 & 0,02 & 0,00 \\
\hline $\mathrm{CE}^{4}$ & 0,00 & 0,00 & 0,02 & 0,00 & 0,02 \\
\hline Total & 100,00 & 100,00 & 100,00 & 100,00 & 100,00 \\
\hline \multicolumn{6}{|l|}{ Valores Calculados* } \\
\hline Cálcio (\%) & 0,63 & 0,63 & 0,63 & 0,53 & 0,73 \\
\hline Energia Met. (Kcal/kg) & 3,23 & 3,23 & 3,23 & 3,18 & 3,28 \\
\hline Fósforo Disp. (\%) & 0,33 & 0,33 & 0,33 & 0,23 & 0,43 \\
\hline Lisina Digestível (\%) & 1,15 & 1,10 & 1,10 & 1,09 & 1,12 \\
\hline Met + Cistina Digest. (\%) & 0,68 & 0,66 & 0,66 & 0,65 & 0,67 \\
\hline Metionina Digestível (\%) & 0,40 & 0,43 & 0,42 & 0,41 & 0,43 \\
\hline Proteína Bruta (\%) & 19,00 & 19,00 & 19,00 & 18,80 & 19,20 \\
\hline Treonina Digestível (\%) & 0,75 & 0,72 & 0,72 & 0,71 & 0,72 \\
\hline Triptofano Digestível (\%) & 0,20 & 0,20 & 0,20 & 0,19 & 0,20 \\
\hline
\end{tabular}

${ }^{1}$ Farelo de Gérmen de Milho Desengodurado; ${ }^{2}$ Composição do Premix Vitamínico Crescimento Suínos por kg de produto: ác. Fólico 351,75mg; ác. pantotênico, $3.500 \mathrm{mg}$; biotina, $18,9 \mathrm{mg}$; cálcio, $52,5 \mathrm{~g}$; niacina, $6.930 \mathrm{mg}$; piridoxina, $630 \mathrm{mg}$; promotor de crescimento, $20.000 \mathrm{mg}$; riboflavina, $1.400 \mathrm{mg}$; selênio, $132 \mathrm{mg}$; tiamina, $350 \mathrm{mg}$; Vit. A, 1.750 .000 UI; Vit. B12, 8.750,7 mcg; Vit. D3, 3.500 UI; Vit. E, $3.500 \mathrm{mg}$; Vit. K3, 700 mg; ${ }^{3}$ Composição do Premix Mineral Suínos por kg de produto: cálcio, $98.800 \mathrm{mg}$; cobalto, $185 \mathrm{mg}$; cobre, $15.750 \mathrm{mg}$; ferro, $26.250 \mathrm{mg}$; iodo, $1.470 \mathrm{mg}$; manganês, $41.850 \mathrm{mg}$; zinco, $77.999 \mathrm{mg}$. ${ }^{4} \mathrm{CE}$ (complexo enzimático) - composição da matriz CE em $200 \mathrm{~g} / \mathrm{t}$ de ração: fósforo total, 500 (\%); 0,100; fósforo disponível, 500 (\%); cácio, 500 (\%); energia digest., $288.000 \mathrm{Kcal} / \mathrm{kg}$; energia metabol., $250.000 \mathrm{Kcal} / \mathrm{kg}$; energia liq., $182.470 \mathrm{Kcal} / \mathrm{kg}$; proteína, 1000 (\%); lisina, 75 (\%); metionina, 45(\%); cistina, 20 (\%); metionina+cistina, 65 (\%); treonina, $20(\%)$; triptofano, 20 (\%); isoleucina, 40 (\%).

Fonte: Elaboração dos autores. 
Tabela 2. Composição percentual e calculada da ração experimental de suínos na fase Crescimento II.

\begin{tabular}{|c|c|c|c|c|c|}
\hline \multirow[b]{2}{*}{ Ingredientes (\%) } & \multicolumn{5}{|c|}{ Tratamentos } \\
\hline & Controle & FGMD $^{1}$ & $\begin{array}{r}\text { FGMD } \\
\mathrm{c} / \mathrm{CE}^{4} \\
\end{array}$ & $\begin{array}{l}\text { FGMD s/ CE } \\
\text { reformulado }\end{array}$ & $\begin{array}{c}\text { FGMD c/ CE } \\
(\text { on top })\end{array}$ \\
\hline Milho grão & 71,68 & 50,30 & 53,02 & 53,02 & 50,30 \\
\hline Farelo de soja $45 \%$ & 25,48 & 24,50 & 23,56 & 23,56 & 24,50 \\
\hline FGMD $^{1}$ FGMD $^{1}$ & 0,00 & 20,00 & 20,00 & 20,00 & 20,00 \\
\hline Óleo de soja & 0,04 & 2,28 & 0,94 & 0,94 & 2,28 \\
\hline Fosfato Bicálcico & 0,97 & 0,87 & 0,33 & 0,33 & 0,87 \\
\hline Calcário & 0,54 & 0,59 & 0,68 & 0,68 & 0,59 \\
\hline L-Lisina & 0,38 & 0,41 & 0,42 & 0,42 & 0,41 \\
\hline Premix Vitamínico ${ }^{2}$ & 0,30 & 0,30 & 0,30 & 0,30 & 0,30 \\
\hline Sal comum & 0,25 & 0,25 & 0,25 & 0,25 & 0,25 \\
\hline DL-Metionina & 0,11 & 0,18 & 0,17 & 0,17 & 0,18 \\
\hline L-Treonina & 0,13 & 0,18 & 0,18 & 0,18 & 0,18 \\
\hline Premix Mineral $^{3}$ & 0,10 & 0,10 & 0,10 & 0,10 & 0,10 \\
\hline L-Triptofano & 0,00 & 0,02 & 0,02 & 0,02 & 0,02 \\
\hline Inerte & 0,02 & 0,02 & 0,00 & 0,02 & 0,00 \\
\hline $\mathrm{CE}^{4}$ & 0,00 & 0,00 & 0,02 & 0,00 & 0,02 \\
\hline Total & 100,00 & 100,00 & 100,00 & 100,00 & 100,00 \\
\hline \multicolumn{6}{|l|}{ Valores Calculados* } \\
\hline Cálcio (\%) & 0,55 & 0,55 & 0,55 & 0,45 & 0,65 \\
\hline Energia Met. (Kcal/kg) & 3,23 & 3,23 & 3,23 & 3,18 & 3,28 \\
\hline Fósforo Disp. (\%) & 0,28 & 0,28 & 0,28 & 0,18 & 0,38 \\
\hline Lisina Digestível (\%) & 1,08 & 1,04 & 1,04 & 1,02 & 1,05 \\
\hline Met + Cistina Digest. (\%) & 0,64 & 0,62 & 0,62 & 0,61 & 0,63 \\
\hline Metionina Digestível (\%) & 0,37 & 0,40 & 0,39 & 0,38 & 0,41 \\
\hline Proteína Bruta (\%) & 18,00 & 18,00 & 18,00 & 17,80 & 18,20 \\
\hline Treonina Digestível (\%) & 0,70 & 0,67 & 0,67 & 0,67 & 0,68 \\
\hline Triptofano Digestível (\%) & 0,19 & 0,19 & 0,19 & 0,18 & 0,19 \\
\hline
\end{tabular}

${ }^{1}$ Farelo de Gérmen de Milho Desengodurado; ${ }^{2}$ Composição do Premix Vitamínico Crescimento Suínos por kg de produto: ác. Fólico 351,75mg; ác. pantotênico, $3500 \mathrm{mg}$; biotina, 18,9 mg; cálcio, 52,5 g; niacina, $6930 \mathrm{mg}$; piridoxina, $630 \mathrm{mg}$; promotor de crescimento, $20000 \mathrm{mg}$; riboflavina, $1400 \mathrm{mg}$; selênio, $132 \mathrm{mg}$; tiamina, $350 \mathrm{mg}$; Vit. A, 1750000 UI; Vit. B12, 8750,7 mcg; Vit. D3, 3500 UI; Vit. E, 3500 mg; Vit. K3, 700 mg; ${ }^{3}$ Composição do Premix Mineral Suínos por kg de produto: cálcio, 98.800 mg; cobalto, $185 \mathrm{mg}$; cobre, $15.750 \mathrm{mg}$; ferro, $26.250 \mathrm{mg}$; iodo, $1.470 \mathrm{mg}$; manganês, $41.850 \mathrm{mg}$; zinco, $77.999 \mathrm{mg} ;{ }^{4} \mathrm{CE}$ (complexo enzimático) - Composição da matriz CE em 200 g/t de ração: fósforo total, 500 (\%); 0,100; fósforo disponível, 500 (\%); cálcio, 500 (\%); energia digest., $288.000 \mathrm{Kcal} / \mathrm{kg}$; energia metabol., $250.000 \mathrm{Kcal} / \mathrm{kg}$; energia liq., $182.470 \mathrm{Kcal} / \mathrm{kg}$; proteína, 1000 (\%); lisina, $75(\%)$; metionina, 45(\%); cistina, $20(\%)$; metionina+cistina, $65(\%)$; treonina, $20(\%)$; triptofano, $20(\%)$; isoleucina, $40(\%)$.

Fonte: Elaboração dos autores. 
Tabela 3. Composição percentual e calculada da ração experimental de suínos na fase Terminação.

\begin{tabular}{|c|c|c|c|c|c|}
\hline \multirow[b]{2}{*}{ Ingredientes (\%) } & \multicolumn{5}{|c|}{ Tratamentos } \\
\hline & Controle & FGMD $^{1}$ & $\begin{array}{l}\text { FGMD } \\
\text { c/ } \mathrm{CE}^{4}\end{array}$ & $\begin{array}{l}\text { FGMD s/ CE } \\
\text { reformulado }\end{array}$ & $\begin{array}{c}\text { FGMD c/ CE } \\
\text { (on top })\end{array}$ \\
\hline Milho grão & 76,41 & 56,18 & 58,91 & 58,91 & 56,18 \\
\hline Farelo de soja $45 \%$ & 20,57 & 19,64 & 18,70 & 18,70 & 19,64 \\
\hline FGMD $^{1}$ & 0,00 & 20,00 & 20,00 & 20,00 & 20,00 \\
\hline Óleo de soja & 0,00 & 1,80 & 0,47 & 0,47 & 1,80 \\
\hline Fosfato Bicálcico & 0,99 & 0,71 & 0,17 & 0,17 & 0,71 \\
\hline Calcário & 0,93 & 0,54 & 0,64 & 0,64 & 0,54 \\
\hline L-Lisina & 0,37 & 0,35 & 0,35 & 0,35 & 0,35 \\
\hline Premix Vitamínico ${ }^{2}$ & 0,30 & 0,30 & 0,30 & 0,30 & 0,30 \\
\hline Sal comum & 0,00 & 0,00 & 0,00 & 0,00 & 0,00 \\
\hline DL-Metionina & 0,15 & 0,19 & 0,18 & 0,18 & 0,19 \\
\hline L-Treonina & 0,14 & 0,14 & 0,15 & 0,15 & 0,14 \\
\hline Premix Mineral $^{3}$ & 0,10 & 0,10 & 0,10 & 0,10 & 0,10 \\
\hline L-Triptofano & 0,03 & 0,03 & 0,03 & 0,03 & 0,03 \\
\hline Inerte & 0,02 & 0,02 & 0,00 & 0,02 & 0,00 \\
\hline $\mathrm{CE}^{4}$ & 0,00 & 0,00 & 0,02 & 0,00 & 0,02 \\
\hline Total & 100,00 & 100,00 & 100,00 & 100,00 & 100,00 \\
\hline \multicolumn{6}{|l|}{ Valores Calculados* } \\
\hline Cálcio (\%) & 0,70 & 0,48 & 0,48 & 0,38 & 0,58 \\
\hline Energia Met.(Kcal/kg) & 3,23 & 3,23 & 3,23 & 3,18 & 3,28 \\
\hline Fósforo Disp. (\%) & 0,28 & 0,25 & 0,25 & 0,15 & 0,35 \\
\hline Lisina Digestível (\%) & 0,95 & 0,87 & 0,87 & 0,86 & 0,89 \\
\hline Met + Cistina Digest. (\%) & 0,63 & 0,59 & 0,59 & 0,58 & 0,60 \\
\hline Metionina Digestível (\%) & 0,38 & 0,38 & 0,38 & 0,37 & 0,39 \\
\hline Proteína Bruta (\%) & 16,20 & 16,20 & 16,20 & 16,00 & 16,40 \\
\hline Treonina Digestível (\%) & 0,64 & 0,58 & 0,58 & 0,58 & 0,58 \\
\hline Triptofano Digestível (\%) & 0,19 & 0,17 & 0,17 & 0,16 & 0,17 \\
\hline
\end{tabular}

${ }^{1}$ Farelo de Gérmen de Milho Desengodurado; ${ }^{2}$ Composição do Premix Vitamínico Terminação Suínos por kg de produto: ác. Fólico, 116,5 mg; ác. Pantotênico, 2333,5 mg; biotina, 5,28 mg; niacina, 5600 mg; piridoxina, 175 mg; promotor de crescimento, $16470 \mathrm{mg}$; riboflavina, 933,3 mg; selênio, $105 \mathrm{mg}$; tiamina, 175,035; Vit. A, 1225000 UI; Vit. B12, 6825 mcg; Vit. D3, 315000 UI; Vit. E, 1400 mg; Vit. K3, 700 mg; ${ }^{3}$ Composição do Premix Mineral Suínos por kg de produto: cálcio, 98.800 mg; cobalto, 185 mg; cobre, $15.750 \mathrm{mg}$; ferro, $26.250 \mathrm{mg}$; iodo, $1.470 \mathrm{mg}$; manganês, $41.850 \mathrm{mg}$; zinco, $77.999 \mathrm{mg} ;{ }^{4} \mathrm{CE}$ (complexo enzimático)Composição da matriz CE em 200 g/t de ração: fósforo total, 500 (\%); 0,100; fósforo disponível, 500 (\%); cálcio, 500 (\%); energia digest., $288.000 \mathrm{Kcal} / \mathrm{kg}$; energia metabol., $250.000 \mathrm{Kcal} / \mathrm{kg}$; energia liq., $182.470 \mathrm{Kcal} / \mathrm{kg}$; proteína, 1000 (\%); lisina, 75 (\%); metionina, 45(\%); cistina, $20(\%)$; metionina+cistina, 65 (\%); treonina, $20(\%)$; triptofano, $20(\%)$; isoleucina, $40(\%)$.

Fonte: Elaboração dos autores.

Os preços dos ingredientes utilizados na elaboração das rações experimentais apresentaram os seguintes valores: milho, R \$ 0,39/kg; farelo de soja, R\$ 0,71/kg; FGMD, R\$ 0,27/kg; óleo de soja, $\mathrm{R} \$ 1,78 / \mathrm{L}$; fosfato bicálcico, R $\$ 0,73 / \mathrm{kg}$; calcário, R\$ 0,076/kg; L-lisina, R\$ 7,00/kg; sal comum, R\$ 0,35/kg; DL-metionina, R\$ $11,73 / \mathrm{kg}$; L-treonina,
$\mathrm{R} \$ 6,36 / \mathrm{kg} ;$ L-triptofano, R\$ 116,00/kg; premix mineral, $\mathrm{R} \$ 2,98 / \mathrm{kg}$; premix vitamínico, $\mathrm{R} \$ 6,22 /$ $\mathrm{kg}$; carvão vegetal (inerte), R\$ 1,74/kg; complexo enzimático, R\$ 26,50/kg.

A viabilidade econômica dos tratamentos foi verificada segundo Bellaver, Fialho e Protas (1985) 
e o Î́ndice de Eficiência Econômica (IEE) e o Índice de Custo Médio (ICM) dos tratamentos foram desenvolvidos segundo Barbosa, Fialho e Ferreira (1992), através das seguintes fórmulas:

$$
\mathrm{IEE}=\mathrm{MC} / \mathrm{CT} \times 100
$$

$\mathrm{ICM}=\mathrm{CT} / \mathrm{MC} \times 100$, em que:

$\mathrm{MC}=$ menor custo médio observado em ração por quilograma de peso vivo ganho entre os tratamentos;

$\mathrm{CT}=$ custo médio do tratamento considerado.

Para o ensaio de digestibilidade realizou-se o método de coleta parcial das fezes através do uso de um marcador fecal $(0,3 \%$ de óxido crômico na ração) por três dias. As fezes foram coletadas duas vezes ao dia, as 8:30 e as 17:30hs, e armazenadas em sacos plásticos e mantidas em temperatura de congelamento até a análise laboratorial. Posteriormente, estas foram descongeladas, secas em estufa de ventilação forçada a $60^{\circ} \mathrm{C}$ por três dias e moídas, sendo analisados os níveis de matéria seca, proteína bruta e extrato etéreo (AOAC, 1990). As determinações do cromo e do fósforo foram realizadas segundo Furukawa e Tsukahara (1966). As mesmas análises foram realizadas nas rações (tratamentos) consumidas durante o ensaio.

Em relação ao manejo pré-abate, a ração foi retirada 12 horas antes do embarque, permanecendo os animais sob dieta hídrica até $\mathrm{o}$ abate. $\mathrm{O}$ embarque dos suínos foi realizado às seis horas da manhã, sendo o tempo de transporte até o frigorífico de aproximadamente uma hora.

Os suínos foram abatidos com peso médio de $98,15 \pm 7,11 \mathrm{~kg}$ e o processo de abate consistiu primeiramente na insensibilização do animal, via corrente elétrica, com equipamento da marca Petrovina ${ }^{\circledR}$ IS 2000 com dois eletrodos, utilizandose 350 volts e 1,3 ampéres. O choque elétrico foi aplicado por um período de aproximadamente três segundos. A sangria foi realizada através do corte dos grandes vasos do pescoço, com os animais na posição vertical, suspensos pelo membro posterior.
Após o abate, escaldagem e evisceração, as carcaças foram divididas ao meio longitudinalmente $\mathrm{e}$ resfriadas à temperatura de $2 \pm 1{ }^{\circ} \mathrm{C}$, por 24 horas, na câmara de resfriamento do frigorífico.

As carcaças foram avaliadas individualmente, sendo obtidos os dados de comprimento de carcaça (CC), espessura de toucinho (ET), profundidade do músculo Longissimus dorsi (PM), área de olho de lombo (AOL), peso da carcaça quente (PCQ), peso da carcaça fria (PCF) e rendimento de carcaça (RC), seguindo as orientações de Bridi e Silva (2009). Os pesos da carcaça quente e da carcaça fria foram utilizados para determinação da porcentagem de perda de peso da carcaça no resfriamento. A espessura de toucinho e a profundidade do músculo Longissimus dorsi foram medidas na altura da última costela a $6 \mathrm{~cm}$ da linha média do corte. A partir dos valores dessas medidas estimou-se o rendimento (RCC) e a quantidade de carne na carcaça (QCC), de acordo com a metodologia estabelecida por Guidoni (2000).

$\mathrm{O} \mathrm{pH}$ da carne foi medido no músculo Longissimus dorsi, na altura da última costela, aos 45 minutos após o abate (pH inicial) e após 24 horas de resfriamento ( $\mathrm{pH}$ final) a aproximadamente $2 \pm$ $1{ }^{\circ} \mathrm{C}$. Após 24 horas de resfriamento foi retirada de cada meia-carcaça esquerda uma amostra do músculo Longissimus dorsi de aproximadamente 15 $\mathrm{cm}$. De cada lombo retirou-se a gordura adjacente, sendo na sequência coletadas 5 amostras do músculo com aproximadamente $2,5 \mathrm{~cm}$ de espessura cada.

Com exceção das amostras de cor e marmoreio, as amostras restantes foram acondicionadas individualmente em sacos plásticos, vedados e armazenados em freezer a $-20{ }^{\circ} \mathrm{C}$ até a realização das análises.

Para a avaliação da cor as amostras foram analisadas 24 horas após o abate, utilizando o colorímetro portátil Minolta ${ }^{\circledR}$ CR10 com esfera de integração e ângulo de visão de $8^{\circ}$, ou seja, iluminação $\mathrm{d} / 8$ e iluminante $\mathrm{C}$. Os componentes $\mathrm{L}^{*}$ (luminosidade), $\mathrm{a}^{*}$ (componente vermelho- 
verde) $\mathrm{e} \mathrm{b}^{*}$ (componente amarelo-azul) foram expressos no sistema de cor CIELAB. Com esses valores calculou-se o ângulo de tonalidade ( $\left.\mathrm{h}^{*}\right)$ pela equação $h^{*}=\tan ^{-1}\left(b^{*} / a^{*}\right)$, e o índice de saturação $\left(\mathrm{c}^{*}\right)$ a partir da equação $\left.\mathrm{c}^{*}=\left[\left(\mathrm{a}^{*}\right)^{2}+\left(\mathrm{b}^{*}\right)^{2}\right)\right]^{1 / 2}$. Estas mesmas amostras também foram avaliadas subjetivamente para o marmoreio, utilizando-se padrões fotográficos (NPPC, 1991), onde foram atribuídas notas de 1 a $5(1=$ traços de marmoreio e $5=$ marmoreio abundante).

A capacidade de retenção de água da carne foi avaliada utilizando-se três metodologias: perda de água por gotejamento, perda de água no descongelamento e perda de água na cocção. A perda de água por gotejamento foi avaliada segundo a técnica descrita por Boccard et al. (1981). A perda de água no descongelamento foi obtida pela diferença do peso da amostra congelada e após o degelo por 24 horas na temperatura de $2 \pm 2{ }^{\circ} \mathrm{C}$; a perda de água na cocção foi obtida pela diferença de peso da amostra descongelada e após o cozimento em forno pré-aquecido a $170{ }^{\circ} \mathrm{C}$, até alcançarem a temperatura interna de aproximadamente $71{ }^{\circ} \mathrm{C}$ (BRIDI; SILVA, 2009).

Para avaliar a maciez da carne, utilizaramse as amostras das análises de perda de água por descongelamento e cocção, sendo que após a cocção, as amostras permaneceram armazenadas por 24 horas a $2 \pm 2{ }^{\circ} \mathrm{C}$. Foram retiradas destas amostras sub-amostras cilíndricas de $2,5 \mathrm{~cm}$ de comprimento e $1 \mathrm{~cm}$ de diâmetro, utilizando-se um amostrador de aço da forma cilíndrica. A força de cisalhamento foi aferida nestas sub-amostras pela lâmina Warner-Bratzler adaptada ao texturômetro Stable Mycro Systems TA-XT2i, perpendicular à orientação das fibras musculares (BOUTON; HARRIS; SHORTHOSE, 1971). As velocidades utilizadas foram de $5 \mathrm{~mm} / \mathrm{s}$ no pré e pós teste e de 2 $\mathrm{mm} / \mathrm{s}$ no teste.
O delineamento experimental para qualidade de carcaça e carne foi em blocos casualisados, sendo 5 blocos de acordo com o peso inicial dos animais, com 5 repetições por tratamento, sendo cada animal uma unidade experimental.

Os dados referentes aos tratamentos e relacionados ao sexo foram submetidos à análise de variância e as médias comparadas pelo Teste de Duncan, sendo utilizado o programa estatístico SAEG (UFV, 1997).

\section{Resultados e Discussão}

Os resultados do desempenho zootécnico nas fases de crescimento I, crescimento I e II e de todo o período experimental (crescimento I e II mais terminaçao) estão apresentados na Tabela 4.

$\mathrm{Na}$ primeira etapa do experimento (fase de crescimento I) não foi observada diferença significativa para nenhum dos parâmetros de desempenho. Pode-se atribuir que devido ao curto intervalo de tempo compreendido entre o início da fase, quando os animais tinham 41,14 $\pm 2,95 \mathrm{~kg}$ de peso vivo, até seu término, quando os suínos possuíam 50,66 $\pm 6,75 \mathrm{~kg}$ de peso vivo (somente oito dias de duração), foi insuficiente para determinar diferenças entre os tratamentos.

Os resultados do presente trabalho nesta primeira fase do experimento identificaram-se com os resultados de Nery et al. (2005), que trabalhando com leitões no início da fase de crescimento também não observaram diferenças para características consumo diário de ração e ganho diário de peso, quando utilizaram complexos enzimáticos contendo amilase, lipases e proteases exógenas em rações à base de milho e farelo de soja. Todavia, deve-se considerar que estes autores utilizaram rações com ingredientes (milho e farelo de soja) reconhecidamente de alta digestibilidade. 
Tabela 4. Médias e desvios-padrão observados do ganho diário de peso (GDP), consumo diário de ração (CDR) e conversão alimentar (CA) de suínos submetidos às rações com e sem a inclusão do complexo enzimático de acordo com as fases experimentais.

\begin{tabular}{lccc}
\hline & \multicolumn{3}{c}{ Fase de crescimento I } \\
\cline { 2 - 4 } Tratamentos (Rações) & \multicolumn{3}{c}{ Parâmetros } \\
\cline { 2 - 4 } & CDR (kg) & GPD (kg) & CA (kg) \\
\hline Controle & $2,36 \pm 0,14$ & $1,13 \pm 0,14$ & $2,13 \pm 0,23$ \\
FGMD* & $2,31 \pm 0,21$ & $1,12 \pm 0,69$ & $2,09 \pm 0,23$ \\
FGMD* c/ CE** & $2,15 \pm 0,16$ & $0,98 \pm 0,14$ & $2,25 \pm 0,30$ \\
FGMD* s/ CE** reformulado & $2,13 \pm 0,37$ & $1,00 \pm 0,18$ & $2,28 \pm 0,43$ \\
FGMD* c/ CE** on top & $2,16 \pm 0,31$ & $1,06 \pm 0,15$ & $2,05 \pm 0,21$ \\
\hline Coeficiente de Variação (\%) & 11,45 & 13,41 & 13,57 \\
\hline \multirow{2}{*}{ Controle } & $2,56 \pm 0,14 \mathrm{a}$ & Fase de crescimento I e II \\
& $2,53 \pm 0,14 \mathrm{a}$ & $1,02 \pm 0,86 \mathrm{a}$ & $2,50 \pm 0,14$ \\
FGMD* & $2,30 \pm 0,16 \mathrm{~b}$ & $0,91 \pm 0,70 \mathrm{bc}$ & $2,52 \pm 0,23$ \\
FGMD* c/ CE** & $2,30 \pm 0,20 \mathrm{~b}$ & $0,90 \pm 0,56 \mathrm{c}$ & $2,55 \pm 0,18$ \\
FGMD* s/ CE** reformulado & $2,36 \pm 0,30 \mathrm{ab}$ & $0,96 \pm 0,86 \mathrm{abc}$ & $2,58 \pm 0,17$ \\
FGMD* c/ CE** on top & 8,25 & 7,46 & 7,12 \\
\hline Coeficiente de Variação (\%) & \multicolumn{3}{c}{ Fase de crescimento I, II e terminação } \\
\hline \multirow{2}{*}{ Controle } & $2,38 \pm 0,12$ & $0,68 \pm 0,63 \mathrm{ab}$ & $3,53 \pm 0,16 \mathrm{~b}$ \\
FGMD* & $2,43 \pm 0,19$ & $0,71 \pm 0,52 \mathrm{ab}$ & $3,43 \pm 0,30 \mathrm{~b}$ \\
FGMD* c/ CE** & $2,26 \pm 0,12$ & $0,66 \pm 0,26 \mathrm{ab}$ & $3,40 \pm 0,12 \mathrm{~b}$ \\
FGMD* s/ CE** reformulado & $2,79 \pm 0,77$ & $0,64 \pm 0,13 \mathrm{~b}$ & $4,33 \pm 0,14 \mathrm{a}$ \\
FGMD* c/ CE** on top & $2,43 \pm 0,20$ & $0,72 \pm 0,51 \mathrm{a}$ & $3,36 \pm 0,17 \mathrm{~b}$ \\
\hline Coeficiente de Variação (\%) & 15,23 & 6,59 & 14,95 \\
\hline
\end{tabular}

Médias seguidas de letras diferentes na mesma coluna, para cada fase, indicam diferença no teste de Duncan $(P<0,05)$

*FGMD $=$ farelo de gérmen de milho desengordurado

$* * \mathrm{CE}=$ complexo enzimático.

Fonte: Elaboração dos autores.

Considerando as fases de crescimento I e II, verificou-se diferença $(\mathrm{P}<0,05)$ para os parâmetros consumo diário de ração e ganho diário de peso. Os animais do tratamento controle, que receberam rações à base de milho e farelo de soja, apresentaram um consumo diário de ração superior $(\mathrm{P}<0,05)$ aos tratamentos com FGMD com complexo enzimático e com FGMD sem complexo enzimático reformulado com menores valores nutricionais. Foi observado menor ganho diário de peso $(\mathrm{P}<0,05)$ para os animais que receberam a ração formulada com FGMD sem o complexo enzimático, reformulado com os menores valores nutricionais, comparado com o grupo tratado com a ração à base de milho e farelo de soja. Isto demonstra o papel positivo do complexo enzimático e dos níveis nutricionais sobre este índice, pois os resultados destes parâmetros para os animais que consumiram rações que continham o complexo enzimático mostraram-se iguais àqueles que consumiram rações formuladas à base de milho e farelo de soja (ração controle).

Todavia, Park et al. (2003), utilizando leitões em fase de crescimento, observaram melhora no ganho diário de peso, na conversão alimentar e ausência de efeitos no consumo diário de ração para leitões alimentados com rações contendo principalmente milho e farelo de soja e um complexo enzimático. Estes resultados identificaram-se parcialmente 
com os obtidos nas fases de crescimento I e II, onde a ausência do complexo enzimático na dieta formulada com $20 \%$ de FGMD, com menor nível nutricional em relação aos demais tratamentos, comprometeu o ganho de peso.

Considerando todo o período experimental (fases de crescimento I, II e terminação), não foram observadas diferenças entre os tratamentos para a característica consumo diário de ração $(\mathrm{P}>0,05)$, porém os animais que consumiram a ração com a enzima on top apresentaram maior ganho diário de peso $(\mathrm{P}<0,05)$ em relação a os animais submetidos ao tratamento cuja ração foi formulada com FGMD sem o complexo enzimático reformulado, com menores níveis nutricionais.

Considerando todas as fases houve piora na conversão alimentar para os animais alimentados com a ração formulada com FGMD sem a inclusão do complexo enzimático e com menores níveis nutricionais $(\mathrm{P}<0,05)$. Entre os demais tratamentos não foi observada diferença para esta característica.

Araque, Contreras e Colina (2009), estudando os efeitos do uso de um complexo enzimático em dietas à base de soja e milho para suínos na fase de terminação, observaram que a adição do complexo afetou positivamente o consumo de ração e a conversão alimentar, sendo que a conversão foi aproximadamente $16 \%$ melhor em relação ao controle (sem o complexo enzimático). Este resultado mais uma vez confirma o papel das enzimas nas rações formuladas com 20\% de FGMD, que levaram os animais a apresentarem padrões de desempenho semelhantes ao do grupo controle.

As dietas constituídas principalmente pelo milho e farelo de soja, como as utilizadas nesta pesquisa, apresentam teores baixos de oligossacarídeos, principal substrato para as enzimas presentes no complexo enzimático empregado. Com a inclusão do FGMD na formulação, um ingrediente com maiores concentrações de polissacarídeos nãoamiláceos (FURLAN; FRAIHA; MURAKAMI, 1997) e menores níveis energéticos (SOARES et al., 2004), a utilização do complexo enzimático resultou em valores de desempenho semelhantes, quando comparados com a ração formulada com milho e farelo de soja. Isto define positivamente a ação das enzimas sobre estes componentes. Neste contexto, para uma decisão quanto ao uso do complexo enzimático e ou de um co-produto como o FGMD, devem ser considerados também os custos das rações formuladas com FGMD, que demandam mais óleo para ajuste dos níveis energéticos, e o custo destas enzimas.

Também o complexo enzimático, por possuir a enzima fitase, pode ter melhorado a disponibilidade de vários nutrientes das rações formuladas com FGMD, que encontram-se complexados com moléculas de ácido fítico (RUIZ et al., 2008), um fator antinutricional altamente presente neste ingrediente (PACHECO et al., 2012).

O uso de enzimas exógenas em rações para suínos em crescimento e terminação sem resultados positivos no desempenho pode ser decorrente da insuficiente melhora da digestibilidade dos nutrientes das dietas avaliadas ou ao fato destas apresentarem, independente das enzimas empregadas, níveis nutricionais satisfatórios para atender as exigências das categorias (fases) testadas. Neste sentido, não foram observadas vantagens sobre os índices de desempenho quando pentosanases, beta-glucanases ou misturas de carboidrases com proteases foram utilizadas em dietas contendo cevada, sorgo ou trigo, como fontes energéticas, e farelo de soja ou canola, como fontes proteicas, em rações para suínos (MAVROMICHALIS et al., 2000; YIN et al., 2001; RODRIGUES et al., 2002; BARRERA et al., 2004; THACKER, 2005). 
Nesta linha de observação não foram registrados resultados que apontassem diferenças significativas entre os tratamentos para os coeficientes de digestibilidade da matéria seca, do fósforo, do extrato etéreo e da proteína bruta (Tabela 5). Neste sentido, os resultados estão em concordância com os obtidos por Ruiz et al. (2008), que não encontraram diferenças nas digestibilidades dos nutrientes quando trabalharam com suínos alimentados com rações à base de milho e farelo de soja suplementadas ou não com um complexo enzimático contendo amilase, celulase, pentosanase, protease e alfa-galactosidase.

Tabela 5. Médias e desvios-padrão observados para o coeficiente de digestibilidade da matéria seca (CDMS), do fósforo (CDP), do extrato etéreo (CDEE) e da proteína bruta (CDPB) de suínos submetidos aos tratamentos experimentais.

\begin{tabular}{lcccc}
\hline Tratamentos & CDMS (\%) & CDP (\%) & CDEE (\%) & CDPB (\%) \\
\hline Controle & $79,09 \pm 8,43$ & $75,68 \pm 10,82$ & $90,04 \pm 1,87$ & $93,95 \pm 2,33$ \\
FGMD* & $86,02 \pm 5,44$ & $66,57 \pm 14,75$ & $93,13 \pm 1,97$ & $92,34 \pm 2,63$ \\
FGMD* c/ CE** & $86,38 \pm 1,77$ & $71,38 \pm 5,35$ & $89,40 \pm 1,80$ & $93,24 \pm 1,06$ \\
FGMD* s/ CE** reformulado & $88,56 \pm 3,43$ & $65,57 \pm 9,59$ & $89,88 \pm 4,57$ & $92,60 \pm 2,80$ \\
FGMD* c/ CE** on top & $88,03 \pm 4,04$ & $69,66 \pm 4,57$ & $92,37 \pm 5,10$ & $92,83 \pm 2,70$ \\
\hline Coeficiente de Variação (\%) & 5,41 & 14,58 & 3,74 & 2,88 \\
\hline
\end{tabular}

*FGMD $=$ farelo de gérmen de milho desengordurado

** $\mathrm{CE}=$ complexo enzimático.

Fonte: Elaboração dos autores.

Para os parâmetros relativos às características de carcaça (Tabela 6) não foram observadas diferenças significativas entre os tratamentos.

Os resultados dos parâmetros de carcaça comumente são um reflexo dos resultados de desempenho. $\mathrm{O}$ índice de conversão alimentar para o período total do experimento foi o parâmetro que apresentou maior diferença entre os tratamentos, mas que exerce pouco efeito sobre as características de carcaça, razão que pode explicar parcialmente a ausência de diferença entre os tratamentos para os parâmetros avaliados.

Os resultados se identificam com os obtidos por Thacker (2005), que não verificou qualquer efeito da utilização de enzimas em dietas à base de milho e farelo de canola sobre as características de carcaça de suínos, quer utilizando enzimas dietéticas individualmente quer usando complexos enzimáticos; e por Thacker e Haq (2008), que trabalhando com dietas com altos níveis de fibra e fatores antinutricionais, como as saponinas, também não observaram efeitos do complexo enzimático dietético sobre as características de carcaça.

Para o sexo foi observada diferença somente para peso de carcaça quente e para o peso de carcaça resfriada, sendo que os machos apresentaram melhores resultados. Estas diferenças refletem a tendência fisiológica que os machos castrados têm em relação às fêmeas de consumirem mais alimento, levando a um maior acúmulo de gordura e músculo na carcaça, justificando os resultados. 
Tabela 6. Médias e desvios-padrão observados do peso de carcaça quente (PCQ) comprimento de carcaça (CC), profundidade do músculo (PM), área de olho de lombo (AOL), peso de carcaça resfriada (PCR) e quantidade de carne na carcaça $(\mathrm{QCC})$ de suínos submetidos aos tratamentos experimentais.

\begin{tabular}{|c|c|c|c|c|c|c|}
\hline \multirow{2}{*}{ Tratamentos } & \multicolumn{6}{|c|}{ Parâmetros } \\
\hline & PCQ (kg) & $\mathrm{CC}(\mathrm{cm})$ & $\mathrm{PM}(\mathrm{mm})$ & $\mathrm{AOL}\left(\mathrm{cm}^{2}\right)$ & PCR (kg) & QCC (kg) \\
\hline Controle & $75,86 \pm 6,87$ & $81,65 \pm 3,10$ & $55,64 \pm 4,57$ & $34,42 \pm 3,23$ & $74,10 \pm 6,79$ & $42,26 \pm 3,68$ \\
\hline FGMD* & $78,60 \pm 4,45$ & $80,60 \pm 1,56$ & $61,01 \pm 6,00$ & $38,22 \pm 5,72$ & $76,84 \pm 4,38$ & $42,54 \pm 2,46$ \\
\hline FGMD* $\mathrm{c} / \mathrm{CE}^{* *}$ & $75,58 \pm 5,06$ & $79,65 \pm 1,86$ & $59,43 \pm 3,53$ & $36,37 \pm 2,67$ & $73,87 \pm 5,09$ & $43,21 \pm 2,07$ \\
\hline $\begin{array}{l}\text { FGMD* s/ CE** } \\
\text { reformulado }\end{array}$ & $75,13 \pm 3,22$ & $80,50 \pm 2,52$ & $59,34 \pm 5,67$ & $37,59 \pm 4,57$ & $73,37 \pm 3,13$ & $41,74 \pm 3,73$ \\
\hline $\begin{array}{l}\text { FGMD* } \mathrm{c} / \mathrm{CE}^{* *} \\
\text { on top }\end{array}$ & $78,74 \pm 6,11$ & $80,90 \pm 2,58$ & $58,79 \pm 5,02$ & $36,77 \pm 4,05$ & $76,96 \pm 6,09$ & $42,86 \pm 2,87$ \\
\hline \multicolumn{7}{|l|}{ Gênero } \\
\hline Macho Castrado & $78,26 \mathrm{a} \pm 5,28$ & $80,52 \pm 5,26$ & $59,41 \pm 2,16$ & $36,07 \pm 4,19$ & $76,59 a \pm 5,26$ & $42,42 \pm 3,09$ \\
\hline Fêmea & $75,45 b \pm 5,20$ & $80,81 \pm 5,09$ & $58,23 \pm 2,60$ & $37,20 \pm 4,22$ & $73,61 \mathrm{~b} \pm 5,09$ & $42,52 \pm 2,64$ \\
\hline $\begin{array}{l}\text { Coeficiente de } \\
\text { Variação (\%) }\end{array}$ & 5,78 & 2,52 & 8,77 & 11,00 & 5,82 & 6,20 \\
\hline
\end{tabular}

*FGMD $=$ farelo de gérmen de milho desengordurado

$* * \mathrm{CE}=$ complexo enzimático.

Fonte: Elaboração dos autores.

Quanto ao pH do músculo Longissimus dorsi (Tabela 7), os maiores valores de $\mathrm{pH}$ inicial (45 minutos pós-abate) $(\mathrm{P}<0,05)$ foram observados nos suínos que receberam ração controle (milho + farelo de soja), com FGMD sem o complexo enzimático e com FGMD com o complexo enzimático on top (que não diferiram entre si), enquanto que os menores valores foram observados nos animais que receberam a ração com FGMD com o complexo enzimático, que diferiram dos demais tratamentos.

Tabela 7. Médias e desvios-padrão observados dos valores de pH inicial e pH final do músculo Longissimus dorsi de suínos submetidos aos tratamentos experimentais.

\begin{tabular}{lcc}
\hline \multirow{2}{*}{ Tratamentos } & \multicolumn{2}{c}{ Parâmetros } \\
\cline { 2 - 3 } & $\mathrm{pH}$ inicial & $\mathrm{pH}$ final \\
\hline Controle & $6,31 \pm 0,27 \mathrm{a}$ & $5,66 \pm 0,96 \mathrm{a}$ \\
FGMD* & $6,09 \pm 0,21 \mathrm{ab}$ & $5,51 \pm 0,20 \mathrm{~b}$ \\
FGMD* c/ CE** & $5,77 \pm 0,26 \mathrm{c}$ & $5,53 \pm 0,89 \mathrm{~b}$ \\
FGMD* s/ CE** reformulado & $5,96 \pm 0,33 \mathrm{bc}$ & $5,52 \pm 0,84 \mathrm{~b}$ \\
FGMD* c/ CE** on top & $6,07 \pm 0,34 \mathrm{ab}$ & $5,56 \pm 0,94 \mathrm{ab}$ \\
\hline Gênero & & $5,56 \pm 0,15$ \\
\hline Macho castrado & $6,05 \pm 0,29$ & $5,60 \pm 0,12$ \\
Fêmeas & $6,03 \pm 0,37$ & 2,23 \\
\hline Coeficiente de Variação (\%) & 4,73 & \\
\hline
\end{tabular}

Médias seguidas de letras diferentes na mesma coluna indicam diferença no teste de Duncan $(\mathrm{P}<0,05)$.

*FGMD $=$ farelo de gérmen de milho desengordurado

**CE= complexo enzimático.

Fonte: Elaboração dos autores. 
O maior valor $(\mathrm{P}<0,05)$ para $\mathrm{pH}$ final foi verificado no tratamento controle (milho + farelo de soja), que não diferiu do grupo que recebeu ração com FGMD mais o complexo enzimático on top, enquanto que os demais tratamentos apresentaram os menores valores $(\mathrm{P}<0,05)$ para este parâmetro. No entanto, os animais alimentados com FGMD mais o complexo enzimático on top apresentaram $\mathrm{pH}$ final semelhante aos demais tratamentos
$(\mathrm{P}>0,05)$. Os valores de $\mathrm{pH}$ obtidos, independente dos tratamentos, encontram-se dentro de uma faixa que os classifica como normais, segundo Warner, Kauffman e Greaser (1997) e Channon, Payne e Warner (2000), não repercutindo negativamente nas características ligadas à qualidade da carne.

Os resultados referentes aos valores de cor $\left(\mathrm{a}^{*}\right.$, b*, L*, c* e h*) do músculo Longissimus dorsi encontram-se na Tabela 8.

Tabela 8. Médias e desvios-padrão dos valores de cor $\left(\mathrm{a}^{*}, \mathrm{~b}^{*}, \mathrm{~L}^{*}, \mathrm{c}^{*}, \mathrm{~h}^{*}\right)$ do músculo Longissimus dorsi de suínos submetidos aos tratamentos experimentais.

\begin{tabular}{|c|c|c|c|c|c|}
\hline \multirow{2}{*}{ Tratamentos } & \multicolumn{5}{|c|}{ Parâmetros } \\
\hline & $\mathrm{L}^{*}$ & $a^{*}$ & $\mathrm{~b}^{*}$ & $\mathrm{c}^{*}$ & $\mathrm{~h}^{*}$ \\
\hline Controle & $52,17 \pm 5,26 \mathrm{~b}$ & $3,27 \pm 0,90 \mathrm{~b}$ & $7,80 \pm 1,37 \mathrm{~b}$ & $8,47 \pm 1,52 \mathrm{~b}$ & $67,37 \pm 4,07$ \\
\hline FGMD* & $57,64 \pm 3,15^{\mathrm{a}}$ & $3,89 \pm 1,41 \mathrm{~b}$ & $9,55 \pm 1,04 \mathrm{a}$ & $10,36 \pm 1,41 \mathrm{a}$ & $68,36 \pm 5,73$ \\
\hline FGMD* $\mathrm{c} / \mathrm{CE}^{* *}$ & $59,45 \pm 2,96^{\mathrm{a}}$ & $4,41 \pm 1,04 \mathrm{ab}$ & $10,07 \pm 0,87 \mathrm{a}$ & $11,02 \pm 1,10 \mathrm{a}$ & $66,56 \pm 4,17$ \\
\hline $\begin{array}{l}\text { FGMD* s/ CE** } \\
\text { reformulado }\end{array}$ & $55,74 \pm 3,52 \mathrm{ab}$ & $4,37 \pm 1,33 \mathrm{ab}$ & $8,88 \pm 1,24 \mathrm{ab}$ & $9,92 \pm 1,60 \mathrm{ab}$ & $64,18 \pm 4,82$ \\
\hline $\begin{array}{l}\text { FGMD* } \mathrm{c} / \mathrm{CE}^{* *} \\
\text { on top }\end{array}$ & $57,36 \pm 5,03^{\mathrm{a}}$ & $5,37 \pm 2,20 \mathrm{a}$ & $9,90 \pm 1,94 a$ & $11,35 \pm 2,55 \mathrm{a}$ & $62,35 \pm 7,54$ \\
\hline \multicolumn{6}{|l|}{ Gênero } \\
\hline Macho castrado & $57,36 \pm 3,91$ & $4,01 \pm 1,37$ & $9,33 \pm 1,28$ & $10,20 \pm 1,56$ & $67,09 \pm 5,53$ \\
\hline Fêmea & $55,51 \pm 5,16$ & $4,42 \pm 1,66$ & $9,09 \pm 1,73$ & $10,16 \pm 2,19$ & $64,72 \pm 5,33$ \\
\hline $\begin{array}{l}\text { Coeficiente de } \\
\text { Variação (\%) }\end{array}$ & 6,89 & 35,24 & 13,72 & 16,22 & 8,54 \\
\hline
\end{tabular}

Médias seguidas de letras diferentes na mesma coluna indicam diferença no teste de Duncan $(\mathrm{P}<0,05)$.

* FGMD= farelo de gérmen de milho desengordurado

$* * \mathrm{CE}=$ complexo enzimático.

Fonte: Elaboração dos autores.

Os menores valores de $\mathrm{L}^{*}$ foram observados no tratamento controle $(\mathrm{P}<0,05)$, enquanto que os demais apresentaram valores maiores para este parâmetro, porém o tratamento com FGMD sem o complexo enzimático reformulado foi semelhante ao grupo controle para esta característica $(\mathrm{P}>0,05)$.

Para o índice de cor $\mathrm{a}^{*}$, o tratamento com FGMD com o complexo enzimático on top apresentou maior valor $(\mathrm{P}<0,05)$ em relação aos tratamentos com ração à base de milho e farelo de soja e com FGMD sem a enzima, não diferindo dos demais tratamentos.
Para as características de cor, b* e c* (croma), o menor valor foi observado para o grupo controle e para os grupos que receberam dietas com FGMD sem o complexo enzimático e reformulado com os menores níveis nutricionais $(\mathrm{P}<0,05)$. Entretanto, foi verificada diferença $(\mathrm{P}<0,05)$ para o grupo controle em relação aos grupos que receberam dietas com o complexo enzimático e com o grupo que foi alimentado com ração com FGMD sem enzimas. Para os valores de $\mathrm{h} *$ não foram observadas diferenças $(\mathrm{P}>0,05)$.

Em geral, as carnes mais claras (maiores valores 
de $\mathrm{L}, \mathrm{b}^{*}$ ) foram aquelas oriundas dos animais que consumiram rações formuladas com FGMD. Este ingrediente tem uma concentração muito baixa de carotenoides comparada com o milho grão (presente em maior concentração na ração controle). Segundo Blessin, Brecher e Dimler (1963), os carotenóides, entre outros fatores, são responsáveis por imprimir cor à carne.

Para o valor de a* (cor verde-vermelho) e para o croma $\left(\mathrm{c}^{*}\right)$, carnes provenientes de animais alimentados com rações com FGMD, ou seja, com níveis mais elevados de ácido fítico, apresentaramse, respectivamente, mais vermelhas e com maior pureza da cor (maior saturação), embora tenha sido verificada para o valor de a* diferença significativa apenas entre o grupo alimentado com ração contendo FGMD mais o complexo enzimático on top e o grupo controle. O ácido fítico, presente em grande quantidade no FGMD, tem um efeito quelante com alguns minerais, em especial com o ferro, minimizando seu efeito na oxidação da mioglobina, levando a carne a uma apresentação mais avermelhada (MINIHANE; RIMBACH, 2002).

Para esta característica deve ser levado em consideração também o elevado coeficiente de variação observado.

Os valores de marmoreio, perda de água por gotejamento, perda de água no descongelamento, perda de água na cocção e força de cisalhamento estão apresentados na Tabela 9, não sendo verificados efeitos dos tratamentos.

Tabela 9. Médias e desvios-padrão observados para marmoreio, perda de água por gotejamento (PAG), perda de água no descongelamento (PAD), perda de água na cocção (PAC) e força de cisalhamento (FC) da carne de suínos submetidos aos tratamentos experimentais.

\begin{tabular}{lccccc}
\hline \multirow{2}{*}{ Tratamentos } & \multicolumn{5}{c}{ Parâmetros } \\
\cline { 2 - 6 } & Marmoreio & PAG (\%) & PAD (\%) & PAC (\%) & FC (kgf) \\
\hline Controle & $2,1 \pm 0,87$ & $4,64 \pm 1,93$ & $10,0 \pm 2,32$ & $34,41 \pm 3,84$ & $5,32 \pm 0,81$ \\
FGMD* & $1,80 \pm 0,79$ & $5,20 \pm 2,26$ & $8,57 \pm 1,81$ & $33,93 \pm 2,69$ & $5,79 \pm 1,27$ \\
FGMD* c/ CE** & $1,9 \pm 0,87$ & $5,69 \pm 2,65$ & $9,95 \pm 4,14$ & $34,66 \pm 4,00$ & $6,15 \pm 1,14$ \\
FGMD* s/ CE** reformulado & $1,3 \pm 0,48$ & $4,68 \pm 2,42$ & $10,41 \pm 2,76$ & $34,80 \pm 3,14$ & $5,48 \pm 0,87$ \\
FGMD* c/ CE** on top & $0 \pm 0,75$ & $4,58 \pm 1,67$ & $7,03 \pm 2,10$ & $34,13 \pm 2,01$ & $5,86 \pm 0,78$ \\
\hline Gênero & $1,91 \pm 0,83$ & $6,34 \pm 1,95$ & $10,13 \pm 3,26$ & $33,14 \pm 2,46$ & $5,28 \pm 0,77$ \\
\hline Macho castrado & $1,70 \pm 0,75$ & $3,60 \pm 1,32$ & $7,94 \pm 2,24$ & $35,60 \pm 3,23$ & $6,18 \pm 1,01$ \\
Fêmea & 43,63 & 35,53 & 30,76 & 8,90 & 15,24 \\
\hline Coeficiente de Variação (\%)
\end{tabular}

*FGMD $=$ farelo de gérmen de milho desengordurado

$* * \mathrm{CE}=$ complexo enzimático.

Fonte: Elaboração dos autores.

Para a característica de marmoreio foi observado um alto valor de coeficiente de variação. Sugerese que esta variação se deve ao método subjetivo de avaliação deste parâmetro, que foi realizado com auxílio de padrões fotográficos, utilizando-se escalas de valores numéricos.

Possivelmente, o maior efeito sobre a qualidade da carne das enzimas presentes em um complexo enzimático esteja associado à fitase. A enzima atua na estrutura do ácido fítico, liberando minerais quelatados como o fósforo e o ferro. $\mathrm{O}$ ferro, reconhecidamente, tem um efeito catalisador de processos de oxidação (MINIHANE; RIMBACH, 2002). Portanto, a enzima, indiretamente, poderia incrementar o efeito oxidante no músculo, piorando a retenção de água neste. Também a fitase, modificando 
a estrutura do ácido fítico, poderia limitar seu papel antioxidante na carne, já comprovado por Harbach et al. (2007), quando o mesmo foi veiculado através de ingredientes (grãos) na ração de suínos. Todavia, não foram observadas diferenças que repercutissem na qualidade da carne. Possivelmente, as concentrações disponibilizadas pelo complexo enzimático sejam insuficientes para influenciar estas características.
Quanto à avaliação econômica dos tratamentos (Tabela 10), observou-se, de acordo com as condições deste experimento e dos preços dos ingredientes, que os melhores índices econômicos e de custo médio foram obtidos para os tratamentos com FGMD com a inclusão do complexo enzimático, considerando a matriz nutricional do complexo enzimático, e no modelo on top, respectivamente.

Tabela 10. Custo médio de ração por quilograma de peso vivo ganho, índice de eficiência econômica (IEE) e índice de custo médio (ICM) de acordo com os tratamentos experimentais.

\begin{tabular}{lccc}
\hline \multirow{2}{*}{ Tratamentos } & \multicolumn{3}{c}{ Parâmetros } \\
\cline { 2 - 4 } & Custo em ração (R\$/kg PV ganho) & IEE (\%) & ICM (\%) \\
\hline Controle & 1,988 & 95,70 & 104,30 \\
FGMD* & 1,994 & 95,48 & 104,52 \\
FGMD* c/ CE** $_{\text {FGMD* s/ CE** reformulado }}^{1,904}$ & 100,00 & 100,00 \\
FGMD* c/ CE** on top & 1,946 & 97,8 & 102,20 \\
\hline
\end{tabular}

*FGMD $=$ farelo de gérmen de milho desengordurado

$* * \mathrm{CE}=$ complexo enzimático.

Fonte: Elaboração dos autores.

\section{Conclusões}

A adição do complexo enzimático em dietas com $20 \%$ de farelo de gérmen de milho desengordurado, com níveis nutricionais e energéticos mais baixos em relação às dietas formuladas com milho e farelo de soja, para suínos em crescimento e terminação, melhorou a conversão alimentar e a eficiência econômica do tratamento, viabilizando seu uso.

\section{Agradecimentos}

À empresa ALLTECH pelo apoio financeiro na condução deste trabalho.

\section{Referências}

ARAQUE, H.; CONTRERAS, E.; COLINA, Y. Performance response to Allzyme ${ }^{\circledR}$ SSF in finishing pigs. In: ALLTECH'S ANNUAL SYMPOSIUM ON SCIENCE AND TECHNOLOGY IN THE FEED AND INDUSTRY, 25., 2009, Lexington Proceedings...
Lexington: [s.n], 2009. CD-ROM.

ASSOCIATION OF OFFICIAL ANALYTICAL CHEMISTS - AOAC. Chemists Official Methods of Analysis. Virgínia: Edited by Kenneth Helrich Arligton, v. 2, 1990. 1298 p.

BARBOSA, H. P.; FIALHO, E. T.; FERREIRA, A. S. Triguilho para suínos nas fases inicial de crescimento e terminação. Revista Brasileira de Zootecnia, Viçosa, MG, v. 21, n. 5, p. 827-837, 1992.

BARRERA, M.; CERVANTES, M.; SAUER, W. C.; ARAIZA, A. B.; TORRENTERA, N.; CERVANTES M. Ileal amino acid digestibility and performance of growing pigs fed wheat-based diets supplemented with xylanase. Journal of Animal Science, Champaign, v. 82, n. 7, p.1997-2003, 2004.

BEDFORD, M. R. Exogenous enzymes in monogastric nutrition - their current value and future benefits. Animal Feed Science and Technology, Amsterdan, v. 86, n. 1, p. 1-13, 2000.

BELlAVER, C.; FIALHO, E. T.; PROTAS, J. F. S. Radícula de malte na alimentação de suínos em crescimento e terminação. Pesquisa Agropecuária Brasileira, Belo Horizonte, v. 20, n. 8, p. 969-974, 1985. 
BEN-HAMED, U.; SEDDIGHI, H.; THOMAS, K. Economic returns of using brewery's spent grain in animal feed. World Academy of Science, Engineering and Technology, v. 50, n. 53, p. 695-698, 2011.

BLESSIN, C.W.; BRECHER, J. D.; DIMLER, R. J. Carotenoids of corn and sorghum. V. Distribution of xanthophylls and carotenes of yellow dent corn. Cereal Chemistry, Pullman, v. 40, n. 1, p. 582-586, 1963.

BOCCARD, R.; BUCHTER, L.; CASSELS, E.; CONSENTINO, E.; DRANSFIELD, E.; HOOD, D. E.; JOSEPH, R. L.; MACDOUGALL, D. B.; RODHES, D. N.; SHON I.; TIMBERGEN, B. J.; TOURAILLE, C. Proceedings for measuring meat quality characteristics in beef production experiments. Beef Production Program: Report of a working group in the Commission of the European Communities, 1981.

BOUTON, P. E.; HARRIS, P. V.; SHORTHOSE, W. R. Effect of ultimate $\mathrm{pH}$ upon the water-holding capacity and tenderness of mutton. Journal of Food Science, Chicago, v. 36, n. 3, p. 435-439, 1971.

BRIDI, A. M.; SILVA, C. A. Métodos de avaliação da carcaça e da carne suína. Londrina: Midiograf, 2009. $97 \mathrm{p}$.

CHANNON, H. A.; PAYNE, A. M.; WARNER, R. D. Halothane genotype, preslaughter handling and stunning method all influence pork quality. Meat Science, Barking, v. 56, n. 1, p. 291-299, 2000.

COSTA, M. C. R.; SILVA, BRIDI, A. M.; FONSECA, N. A. N.; OBA, A.; SILVA, R. A. M.; SILVA, P. A.; YWAZAKI, M. S.; DALTO, D. B. Estabilidade lipídica do pernil e da linguiça frescal de suínos tratados com dietas com alta concentração de ácido fítico. Semina. Ciências Agrárias, Londrina, v. 32, n. 4, p. 1863-1863, 2011.

FERREIRA, A. S.; ARAÚJO, W. A. G.; SILVA, B. A. N. Nutrição e manejo da alimentação de porcas na gestação e lactação em momentos críticos. In: SEMINÁRIO DE AVES E SUÍNOS - AVISUI, 2007, 7., Belo Horizonte. Anais...Belo Horizonte: Gessuli Editora, 2007. p. 71-95.

FURLAN, A. C.; FRAIHA, M.; MURAKAMI, A. E. Utilização de complexo multienzimático em dietas de frangos de corte contendo triticale. 1. Ensaio de digestibilidade. Revista Brasileira de Zootecnia, Viçosa, v. 26, n. 4, p. 759-764, 1997.

FURUKAWA, A. A.; TSUKAHARA, H. On the acid digestion for the determination of chromic oxide as index substance in the study of digestibility of fish feed. Bulletin of the Japanese Society of Fisheries, Minato, v. 32, n. 6, p. 502-506, 1966.
GENLAI, L.; XIAO, W.; MINGXIN, L. Effects of corn DDGS and Allzyme SSF supplementation on growth performance, fecal microflora, and nitrogen and phosphorus digestibility in growing-finishing pigs. In: ALLTECH'S ANNUAL SYMPOSIUM, 25., 2009, Lexington. Proceedings...Lexington: [s.n], 2009. CDROM.

GUIDONI, A. L. Melhoria de processos para tipificação e valorização de carcaças suínas no Brasil. In: CONFERENCIA INTERNACIONAL VIRTUAL SOBRE A QUALIDADE DE CARNE SUÍNA, 2000, Concórdia. Anais... Concórdia: EMBRAPA-CNPSA, 2000. p. 221-234.

HARBACH, A. P. R.; COSTA, M. C. R.; SOARES, A. L.; BRIDI, A. M.; SHIMOKOMAKI, M.; SILVA, C. A. Da; IDA, E. I. Dietary corn germ containing phytic acid prevents pork meat lipid oxidation while maintaining normal animal growth performance. Food Chemistry, London, v. 100, n. 4, p. 1630-1633, 2007.

MAVROMICHALIS, I.; HANCOCK, J. D.; SENNE, B. W.; GUGLE, T. L.; KENNEDY, G. A.; HINES, R. H.; WYATT, C. L. Enzyme supplementation and particle size of wheat in diets for nursery and finishing pigs. Journal of Animal Science, Champaign, v. 78, n. 12, p. 30863095, 2000.

MINIHANE, A. M.; RIMBACH, G. Iron absorption and the iron binding and anti-oxidant properties of phytic acid. International Journal of Food Science and Technology, Oxford, v. 37, n. 7, p. 741-748, 2002.

MOREIRA, I.; RIBEIRO, C. R.; FURLAN, A. C.; SCAPINELLO, C.; KUBTSCHENKO, M. Utilização do farelo de gérmen de milho desengordurado na alimentação de suínos em crescimento e terminação - digestibilidade e desempenho. Revista Brasileira de Zootecnia, Viçosa, v. 31, n. 6, p. 2238-2246, 2002.

NATIONAL PORK PRODUCERS COUNCIL - NPPC. Procedures to evaluated market. 3. ed. Des Moines: Iowa, 1991

NERY, V. L. H.; LIMA, J. A. F.; MELO, R. C. A.; FIALHO, E. T. Adição de enzimas exógenas para leitões dos 10 aos $30 \mathrm{~kg}$ de peso. Revista Brasileira de Zootecnia, Viçosa, v. 29, n. 3, p. 794-802, 2005.

PACHECO, G. D.; LOZANO, A. P. V. S. L.; SILVA, R. A. M.; DALTO, D. B.; AGOSTINI, P. S.; FONSECA, N. A. N.; BRIDI, A. M.; SILVA, C. A. Utilização do farelo de gérmen de milho desengordurado, como fonte de fitato, associado à fitase em rações de suínos: efeitos sobre a qualidade da carne e da linguiça tipo frescal. Semina. Ciências Agrárias, Londrina, v. 33, n. 2, p. 819$828,2012$. 
PARK, J. S.; CARTER, S. D.; SCHNEIDER, J. D.; MORILLO, T.B. Effects of a solid-state fermented phytase on growth performance, bone traits and phosphorus digestibility of growing pigs fed corn-soybean meal diets containing wheat middling. Animal Science Research, Stillwater, v. 1, n. 1, p. 1-5, 2003. Disponível em: <www. ansi.okstate.edu/research/2003rr>. Acesso em: 20 ago. 2012.

RODRIGUES, P. B.; FREITAS, R. T. F.; FIALHO, E. T.; SILVA, H. O.; GONÇALVES, T. M. Digestibilidade dos nutrientes e desempenho de suínos em crescimento e terminação alimentados com rações à base de milho e sorgo suplementados com enzimas. Revista Brasileira de Milho e Sorgo, Sete Lagoas, v. 1, n. 2, p. 91-100, 2002.

ROSTAGNO, H. S.; ALBINO, L. F. T.; DONZELE, J. L.; GOMES, P. C.; OLIVEIRA, R. F.; LOPES, D. C.; FERREIRA, A. S.; BARRETO, S. L. T. Tabelas brasileiras para aves e suínos: composição de alimentos e exigências nutricionais. Viçosa: UFV, 2005. 153 p.

RUIZ, U. S.; THOMAZ, M. C.; HANNAS, M. I.; FRAGA, A. L.; WATANABE, P. H.; SILVA, S. Z. Complexo enzimático para suínos: digestão, metabolismo, desempenho e impacto ambiental. Revista Brasileira de Zootecnia, Viçosa, v. 37, n. 3, p. 458-468, 2008.
SOARES, L. L. P.; SILVA, C. A.; PINHEIRO, J. W.; FONSECA, N. A. N.; CABRERA, L.; HOSHI, E. H.; SILVA, M. A. A. da; CANTERI, R. C. Farelo de gérmen de milho desengordurado na alimentação de suínos em crescimento e terminação. Revista Brasileira de Zootecnia, Viçosa, MG, v. 33, n. 6, p. 1768-1776, 2004.

THACKER, P. A. Effect of xylanase and protease on the performance of growing-finishing pigs fed corn-based diets. Journal of Applied Animal Research, Izatnagar, v. 28, n. 11, p. 17-23, 2005.

THACKER, P. A.; HAQ, I. Nutrient digestibility, performance and carcass traits of growing-finishing pigs fed diets containing graded levels of dehydrated lucerne meal. Journal of the Science and Food Agriculture, London, v. 88, n. 11, p. 2019-2025, 2008.

UNIVERSIDADE FEDERAL DE VIÇOSA - UFV. Manual de utilização do programa SAEG (Sistema de análises estatísticas e genéticas). Versão 7.1. Viçosa, MG, 1997. $150 \mathrm{p}$.

WARNER, R. D.; KAUFFMAN, R. G.; GREASER, M. L. Muscle protein changes postmortem in relation to pork quality traits. Meat Science, Barking, v. 45, n. 3, p. 339-352, 1997.

YIN, Y. L.; McEVOY, J. D. G.; SCHULZE, H.; MCCRACKEN, K. J. Effects of xylanase and antibiotic addition on ileal and faecal apparent digestibilities of dietary nutrients and evaluating $\mathrm{HCl}$-insoluble ash as a dietary marker in growing pigs. Animal Science, Penicuik, v. 72, n. 3, p. 95-103, 2001. 
